\title{
Antenatal education in India: an appraisal abstract
}

\author{
Volume 5 Issue 7 - 2016
}

\section{Introduction}

Antenatal education has the aim to provide expectant parents with strategies for dealing with pregnancy, childbirth and parenthood. Studies showed that it was useful to the pregnant women in different aspects such as the preparation for the parenthood. However, its relationship with maternal-fetal outcomes was not reviewed much. The pregnant women can obtain useful information related to childbearing and childbirth from midwives once they have started their antenatal visits. Antenatal education can be delivered in the form of the advice given during antenatal visits, the information booklets or pamphlets obtained, and the structured midwife-led antenatal education programme with $3 \mathrm{D}$ animated video.

Understanding how much do primigravid women express right information related to the education on selected antenatal exercise is the query of the study. Therefore 600 primigravid women in both groups were assessed to determine the level of knowledge on selected antenatal exercises like breathing exercise, pelvic floor exercise and relaxation technique. A structured knowledge questionnaire was prepared with 35 items with total score of 35 knowledge questionnaires. The level of the knowledge was divided as inadequate knowledge, moderate knowledge and adequate knowledge. The level of knowledge was classified as adequate, moderately adequate and inadequate. The knowledge of primigravid women was compared between the groups (experimental and control) and also before and after the video assisted teaching programme.

The primigravid women were assessed for their level of knowledge during their first visit. The result showed that all the women in both groups had inadequate knowledge irrespective of the group they belong to. This status of art prompted for well structured education to women on exercise to comfort labor process. The content of structured antenatal education programme delivered with the help of $3 \mathrm{D}$ animated video program on pregnancy, labor, meaning and benefits of selected antenatal exercises, benefits, do's \& don'ts, types of exercises, exercises on pregnancy, exercises on $1^{\text {st }}, 2^{\text {nd }} \& 3^{\text {rd }}$ stage of labor, purposes of each exercises, and techniques.

The structured antenatal education delivered to the experimental group mothers in two sessions and post test was given after 7 days in experimental and control group mothers to assess gain in knowledge using the same structured knowledge questionnaire. Collected data was analysed by using both descriptive and inferential statistical method. To evaluate the effectiveness of video assisted teaching programme ' $t$ ' test and chi square test was used. The calculated ' $t$ ' value 33752.86 is significantly higher than the table value 2.22 at 0.000 level of significance. This study indicates that there is significant difference between the pre test and post test knowledge score and video assisted teaching programme is proved to be effective in improving knowledge among antenatal mothers in experimental group. With regard to age, education, monthly income, obtain chi-square value were significant at 0.005 level.

This study proved that knowledge level of primigravid women in

\author{
Emi John Prince \\ Department of Post Graduate Studies, Institute of Health and \\ Management, Australia
}

\begin{abstract}
Correspondence: Emi John Prince, Department of Post Graduate Studies, Course coordinator, Institute of Health and Management, 33 Argyle Street, Parramatta NSW 2150, Australia, Tel 6I434474830Email yemiprince@hotmail.com
\end{abstract} Received: December 29, 2016 | Published: December 30,
2016

the experimental group showed significant improvement on selected antenatal exercises after video assisted teaching programme. Antenatal education program on selected antenatal exercises should be a routine activity and a service to be delivered by nurses and midwives in the antenatal, outpatient department and in the in labor unit. ${ }^{1-5}$

In resource poor setting countries, video assisted antenatal education program can be adopted in the antenatal clinics to enhance the knowledge of new antenatal mothers on selected antenatal exercises and labour outcomes on mother and fetus. Ministry of health of nation and stakeholders are responsible to make this as policy and its intervention to the country. Therefore, antenatal education deserves to be evaluated, training and education to healthcare providers to use effective methods based on adult learning principles remains as indispensable part of good health development in resource poor settings.

\section{Acknowledgments}

None.

\section{Conflicts of interest}

None.

\section{References}

1. Prince EJ, Seshan V. The Effect Of Selected Antenatal Exercises In Reduction Of Labour Pain Among Primigravid Women: Implication For Practice. Journal of South Asian federation of Obstetrics and Gynecology. 2015;7(3):185-190.

2. Clapp JF. Exercising Through Your Pregnancy. Addicus Books, Nebraska, Omaha. 2002;100(5):997-1002.

3. Ghodsi Z, Asltoghiri M, Hajiloomohajerani M. Exercise and pregnancy: duration of labor stages and Perineal tear rates. Procedia - Social and Behavioral Sciences. 2012;31:441-445. 
4. Fenwick J, Gamble J, Nathan E, et al. Pre-And Postpartum Levels Of Childbirth Fear And The Relationship To Birth Outcomes In A Cohort Of Australian Women. J Clin Nurs. 2009;18(5):667-677.
5. Kassebaum NJ, Lopez AD, Murray CJL. A comparison of maternal mortality estimates from GBD 2013 and WHO. The Lancet. 2014;384(9961):2209-2210. 